\title{
Kinerja Promosi Jasa Belitung Utama Tour and Travel Bandung dalam Berbisnis
}

\author{
Fahriza Junizar $^{1}$, Ute Lies Siti Khadijah², Edwin Rizal ${ }^{2}$ \\ 1 Program Studi Magister Pariwisata Berkelanjutan Sekolah Pascasarjana Universitas Padjadjaran \\ ${ }^{2}$ Fakultas Ilmu Komunikasi, Universitas Padjadjaran, Jl. Raya Bandung Sumedang KM.21, Sumedang \\ w-mail: junizar.fahriza7@gmail.com,ute.lies@unpad.ac.id, edwin.rizal@unpad.ac.id
}

\begin{abstract}
ABSTRAK
Peran biro perjalanan wisata dalam mengembangkan perekonomian dengan permintaan pasar yang cepat berubah, para pemerintah daerah dan pelaku industri pariwisata mempunya peran yang cukup penting dalam pencapaian kesuksesan di bidang pariwisata. Terutamanya di biro perjalanan wisata, selain mengembangkan bisnisnya, biro perjalanan wisata juga memiliki dampak terhadap kemajuan pariwisata di suatu kota. Menurut Hasibuan (2002:160), Kinerja diartikan sebagai hasil kerja yang telah dicapai oleh seseorang dalam menjalankan tugas-tugasnya berdasarkan kecerdasannya, usaha serta kesempatan yang dilakukannya. Banyaknya paket wisata yang tersedia saat ini, membuktikan keberagaman minat dari wisatawan dan permintaan pasar, itu juga bisa membuktikan dengan banyaknya kunjungan berbagai motivasi yang datang ke Kota Bandung. Dalam makalah ini metode yang digunakan adalah kualitatif, untuk mengetahui bagaimana strategi yang dilakukan Jasa Belitung Utama (JBU) Tour And Travel Bandung. Penelitian ini menunjukan hasil bahwa strategi bisnis yang paling dilakukan dari pemilik JBU ini adalah dengan pemasaran yaitu promosi melalui periklanan dan personal selling.
\end{abstract}

kata kunci: Kinerja, Jasa Belitung Utama, Bandung

\begin{abstract}
The role of the travel agency in developing the economy with rapidly changing market demand, local governments and the tourism industry have an important role in achieving success in the field of tourism. Especially in a travel agency, in addition to developing its business, a travel agency also has an impact on the progress of tourism in a city. According to Hasibuan (2002: 160), Performance is defined as the results of work that has been achieved by someone in carrying out their duties based on intelligence, effort and opportunity they do. The number of tour packages available today, proving the diversity of interests of tourists and market demand, it can also prove with the many visits that come from various motivations to the city of Bandung. In this paper the method used is qualitative, to find out how the strategies are carried out by the Main Belitung Services (JBU) Bandung Tour And Travel. This research shows the results that the most carried out business strategy of $J B U$ owners is by marketing namely promotion through advertising and personal selling.
\end{abstract}

keywords: Performance, Jasa Belitung Utama, Bandung

\section{PENDAHULUAN}

Demi mewujudkan target kunjungan wisata yang dibuat oleh Kementrian Pariwisata pada tahun 2019 yaitu sejumlah 17 juta wisatawan mancanegara dan 270 juta wisatawan nusantara. Diperlukanlah suatu strategi bisnis yang baik diantaranya adalah bagaimana suatu wisausahawan melakukan pemasaran demi keberlangsungan bisnisnya dan mengembangkan daerah sekitarnya. PT. Jasa Belitung Utama Tour And Travel (JBU) didirikan pada tahun 1991 di Belitung dengan izin tour dan travel international dan fokus bisnis menyediakan jasa perjalanan wisata international dan domestik. Pada tahun 2008 Jasa Belitung Utama membuka anak cabang pertamanya di Bandung di Jl. Pratista Raya No.48 Antapani. Langkah Jasa Belitung Utama untuk promosi mengenalkan produk-produknya ke konsumen (perusahaan) dengan menggunakan personal selling. JBU selalu melakukan pemasaran melalui promosi yaitu dengan perikalanan dan personal selling pada saat high seasson biasanya pertengahan tahun dan menuju akhir tahun. Periklanan di JBU difungsikan untuk merangsang dan menaikan jumlah viewers dan personal selling ini yang ditugaskan untuk follow up hasil dari rangsangan dari periklanan ini, biasanya JBU mengiklankan melalui media cetak dan media elektronik seperti Instagram, Youtube.

\section{METODOLOGI}

Menurut Sugiyono (2013:2) metode penelitian merupakan cara ilmiah untuk mendapatkan data dengan tujuan dan kegunaan tertentu. Metodologi juga merupakan analisis teoritis mengenai suatu cara atau metode. Bimo Walgito (2010:92) studi kasus merupakan suatu metode untuk menyelidiki atau mempelajari suatu riwayat hidup. Pada metode studi kasus ini diperlukan banyak informasi guna mendapatkan bahan-bahan yang agak luas. Peneliti menggunakan pendekatan kualitatif karena ingin mengetahui kinerja Jasa Belitung Utama Tour And Travel 
dengan menggunakan data - data dan hasil yang didapatkan dengan cara wawancara. Populasi dalam penelitian ini adalah 14 staff yang berada di keseluruhan divisi yang bekerja di Jasa Belitung Utama Tour And Travel.

Selain itu, sampel yang akan peneliti gunakan untuk pedoman wawancara yaitu staff yang bekerja di bidang promosi khususnya sales person personal selling. Sampel ialah populasi dalam bentuk kecil, Arifin (2011:215). Dengan menggunakan studi kasus, jumlah sampel ditentukan dan dibatasi dengan staff yang bekerja di bagian promosi yang berjumlah 5 orang di Jasa Belitung Utama Tour And Travel.

Teknik yang digunakan peneliti dalam mengumpulkan data antara lain : a. Wawancara Menurut Stewart dan Cash (2012) "Wawancara adalah proses komunikasi interaksi antara dua pihak yang setidaknya satu diantara mereka memiliki tujuan serius yang telah ditetapkan dan melibatkan proses tanya jawab tentang sesuatu"

Wawancara dilakukan peneliti guna mendapatkan data primer dalam penelitian ini yaitu strategi pemasaran yang dilakukan Jasa Belitung Utama Tour And Travel. b. Studi Pustaka "Studi kepustakaan adalah teknik pengumpulan data dengan mengadakan studi penelaahan terhadap buku- buku, literatur-literatur, catatan-catatan, dan laporan-laporan yang ada hubungannya dengan masalah yang dipecahkan.” (Nazir:2005) Dalam penelitian ini peneliti menggunakan teknik pengumpulan data studi pustaka untuk memperoleh data awal penelitian serta data- data pendukung penelitian seperti data hasil penjualan yang dilakukan oleh bagian pemasaran, data produk yang terjual, dan lain - lain yang berasal dari Jasa Belitung Utama Tour And Travel.

\section{HASIL DAN PEMBAHASAN}

\section{Profesionalisme}

Di dalam sikap profesionalisme, 3 sales person melakukan pencarian dan menghubungi client sebanyak 5 kali dalam sehari, 2 sales person tetap follow up kepada client walaupun tidak terlalu responsif dikarenakan sales person masih adanya peluang untuk keberhasilan penawaran, sedangkan 1 sales person tidak menindaklanjuti karena client kurang responsif maka sales person beranggapan tidak adanya keseriusan dari pihak client. Dari point follow-up cukup bagus, karena 2 dari 3 sales person masih optimis dalam melakukan penawaran, sedangkan 1 sales person kurang memiliki optimis apabila client tidak terlalu responsif terhadap penawaran.

Dalam melakukan pendekatan awal 2 sales person lebih suka mengikuti aturan dalam berbisnis yaitu secara formal dan bertemu di

kantor client untuk membuktikan keseriusan dalam berbisnis, sedangkan 1 sales person melakukan pertemuan dengan membuat janji diluar kantor dari client untuk menemukan suasana yang baru dan tidak terlalu canggung tapi tetap serius dalam berbisnis, cara yang dilakukannya sangat berbeda, sales person yang melakukan pertemuan diluar kantor client akan memanjakan client dengan membelikan makanan/minuman yang membuat client menjadi segan dan menanggapi dengan serius dalam berbisnis.

Kendala yang banyak di dapatkan adalah terlalu kakunya 2 sales person yang melakukan presentasi di kantor karena gugup/grogi yang membuat client ragu dan susah dalam menerima informasi dari sales person.

Dalam mengatasi keluhan 2 sales person yang bertemu client di kantornnya menampung keluhan/pertanyaan dan merundingkan dengan pihak Jasa Belitung Utama untuk diberikan saran, tetapi ini memakan waktu lama dalam mendapatkan jawaban sehingga client mengeluh karena sales person tidak cepat tanggap.

Sedangkan sales person yang melakukan presentasi diluar kantor client sedikit mendapatkan keluhan karena client sudah mendapatkan informasi yang jelas, keluhan yang diberikan oleh client adalah kurang jelasnya brosur/buku produk yang diberikan client.

Dari aspek profesionalisme permasalahan ada di bagian pencarian dan follow up kepada client karena 1 sales person kurang optimis bila client tidak terlalu menanggapi tawaran dari sales person, dan permasalahan lainnya adalah saat sales person yang bertemu client di perusahaan client tersebut, sales person kurang percaya diri dan cepat tanggapnya sales person dalam melakukan tanya jawab, menangani keluhan dari client. Jadi point untuk sikap profesionalisme masih belum cukup baik karena 2 sales person sering mendapatkan masalah saat bertemu client.

\section{Negosiasi}

Untuk menutup komunikasi semua sales person akan melakukan negosiasi langsung dan menanyakan keputusan apakah client membeli produk tersebut, apabila belum

adanya kesepakatan maka sales person akan menjadwalkan ulang untuk pertemuan berikutnya.

Strategi yang dipersiapkan oleh sales person adalah memberikan potongan harga dan foc (free of charge) kepada client yang telah diberitahukan oleh Jasa Belitung Utama Tour and Travel.

Dalam menentukan tipe dan karakter client, sales person menilai dari respon pertama kali dan mengamati selama pertemuan dan presentasi berlangsung, tipe client yang

banyak didapatkan oleh sales person yang bebrtemu di kantor client adalah tipe yang pendiam, tertutup, sedangkan tipe client yang bertemu sales person diluar kantor memiliki sifat yang gampang berinteraksi, to the point, dan responsif.

Untuk point negosiasi cukup baik dikarenakan sales person bisa melakukan tindakan yang cepat bila tidak adanya kesepakatan, strategi yang diberikan Jasa Belitung Utama sudah cukup baik, tetapi permasalahannya ada pada 2 sales person yang tidak memberitahukan penawaran dari Jasa Belitung Utama. 


\section{Relationship Marketing}

Dalam menghubungi client yang pernah membeli produk Jasa Belitung Utama, sales person meminta testimoni dari produk yang client gunakan, testimoni tersebut yang akan menjadi evaluasi produk untuk divisi tour. Sejauh ini sales person sudah melaksanakan tugas tersebut cukup baik, dikarenakan tidak adanya keterlambatan dalam memberikan informasi tersebut karena bisa dilakukan secara online.

Divisi promosi melakukan meeting internal secara rutin setiap minggunya untuk membahas permasalahan yang ada, dan

melengkapi data client yang pernah menggunakan produk Jasa Belitung Utama,

hal ini berlangsung baik, karena memudahkan untuk jangka waktu berikutnya dalam memilih dan menawarkan produk yang tepat juga harga yang sesuai dengan latar belakang data client tersebut. Untuk point relationship marketing bisa dikatakan cukup baik karena semua sudah berjalanan sesuai dengan prosedur.

\section{Selling Person Role}

Dalam sikap menanggapi keluhan, 2 sales person yang bertemu secara formal mendapatkan keluhan diakrenakan kurang tanggapnya dalam menjawab pertanyaan langsung, dan membutuhkan waktu lebih untuk meminta saran dari Jasa Belitung Utama, terbatah-batahnya dalam menjawab membuat ragu client juga menjadi kendala sekarang ini, untuk sales person yang bertemu secara semi-formal sejauh ini belum ada keluhan dari client. Kurangnya rasa percaya diri dalam sales person dalam mengutarakan pendapat secara langsung dan kurangnya pengalaman kerja pada bagian sales person.

\section{Manajerial}

Dalam meningkatkan motivasi saat bekerja Jasa Belitung Utama Tour and Travel memberikan bonus kepada karyawan yang berhasil dalam pencapaian target setiap bulannya, bonus tersebut berupa incentive yang dilakukan bersama karyawan yang berhak mendapatkan bonus tersebut.

Di dalam divisi promosi diadakan gathering di rumah makan dan outting setahun sekali yang biasanya di akhir tahun di dalamnya berisikan acara team building agar saling erat menjalin hubungan kerja dan kekompakan dalam bekerja, sejauh ini cara ini cukup dikarenakan saling membantunya karyawan yang berada di divisi promosi

\section{DAFTAR PUSTAKA}

Aaker, David. 2001. Marketing Research, Seventh Edition. USA: John Wiley \& Sons, Ind.

Alma, Buchari, 2004, Manajemen Pemasaran dan Pemasaran Jasa, Cetakan Keenam, Alfabeta, Bandung.
Almanshur Fauzan, Ghony Djunaidi (2012).

Metodologi Penelitian kualitatif, JogJakarta:

Ar-Ruzz Media

Arifin, Zainal. (2011). Penelitian Pendidikan: Metode dan Paradigma Baru. Bandung: PT.

Remaja Rosdakarya

Arikunto, (2002:108) Prosedur Penelitian, Suatu Pendekatan Pratik : Jakarta

Armstrong, dan Kotler 2003. "Dasar - dasar

Pemasaran, Jilid 1, Edisi Kesembilan"

Jakarta : Indeks Gramedia

Desky. 2003. Pengantar Biro Perjalanan Wisata. Yogyakarta : PT Adicipta Karya Nusa.

Dharmmesta dan Irawan, 2000. Manajemen Pemasaran Modern, Edisi II, Liberty, Yogyakarta.

Fandy Tjiptono, Manajemen Jasa, Penerbit

Andi Yogyakarta 2000

Gordon B. Davis (2003). Sistem Informasi Manajemen. Yogyakarta : Andi Offset. Herdiansyah, haris. 2010. Metodologi

Penelitian Kuantitatif. Jakarta: Salemba Humanika.

Husein Umar, 2005, "Metode Penelitian Untuk Skripsi dan Tesis Bisnis", Jakarta : PT. Raja Grafindo Persada.

Kotler, Philip dan Gary Armstrong. 2008. PrinsipPrinsip Pemasaran. Erlangga. Jakarta Kotler, Philip. Dan Gary. 2014. Principle Of Marketing. 15th edition, New Jersey: Pearson Prentice Hall

Kismono, Gugup, Pengantar Bisnis, Edisi I, Cetakan I, BPFE, Yogyakarta, 2001. Margono, 2004, Metodologi Penelitian Pendidika, Jakarta: Rineka Cipta.

Marketing Terhadap Kepuasan Pelanggan Dalam Industri Jasa Asuransi Jiwa", Ventura. Vol. 6. (127-146).

Muhammad Nazir, 2005, Metode Penelitian, Ghalia Indonesia, Jakarta

Philip Kotler dan Amstrong, 2012; Dasar- Dasar Pemasaran, jilid 1 dan 2, Jakarta.

Prasasti, Dwi Rizki, Herizon Chaniago, dan Yudi Sutarso, 2003, "Pengaruh Relationship Rahardjo, Susilo dan Gudnanto. (2011). Pemahaman Individu Tekhnik Non Tes. Kudus: Nora Media Enterprise.

Sumarni, Murti dan John Soeprihanto. 2010. Pengantar Bisnis (Dasar-dasar Ekonomi Perusahaan). Edisi ke 5. Yogyakarta: Liberty Yogyakrta

Suryana. (2001). Kewirausahaan. Jakarta: Salemba Empat

Sutopo. 2006. Metodologi Penelitian Kualitatif. Surakarta: UNS

Tjiptono, Fandy, 2008, Strategi Pemasaran, Edisi 3, ANDI: Yogyakarta.

Tours and Travel Marketing. Oka A. Yoeti. 2003. Pradnya Paramita. Jakarta 